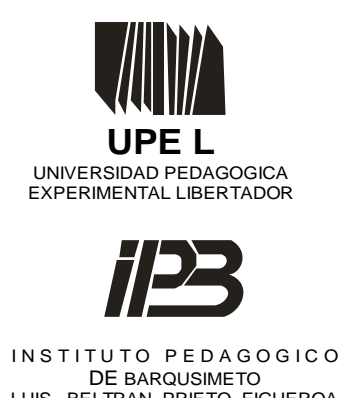

DE BARQUSIMETO
LUIS BELTRAN PRIETO FIGUEROA

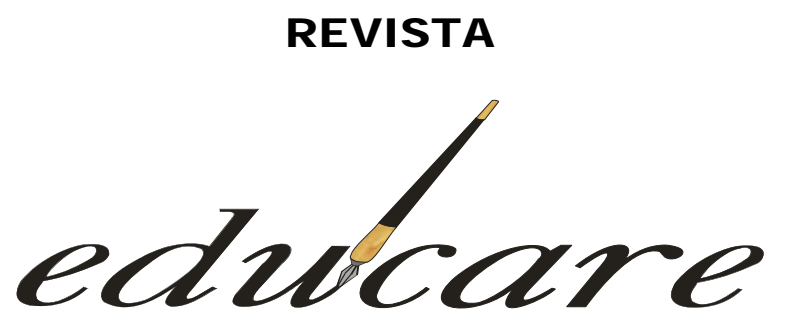

Órgano Divulgativo de la Subdirección de Investigación y Postgrado del Instituto Pedagógico de Barquisimeto "Luis Beltrán Prieto

BARQUISIMETO - EDO. LARA - VENEZUELA

NUEVA ETAPA

FORMATO ELECTRÓNICO

DEPOSITO LEGAL: ppi201002LA3674

Volumen $18 \mathrm{~N}^{\circ} 1$

ISSN: 2244-7296

Enero - Abril 2014

\title{
APROXIMACIÓN EPISTÉMICA A LA EDUCACIÓN LITERARIA
}

EPISTEMIC APPROXIMATION TO LITERARY EDUCATION

\section{Wilfredo lllas Ramírez*}

*UNIVERSIDAD DE CARABOBO (UC) 


\title{
APROXIMACIÓN EPISTÉMICA A LA EDUCACIÓN LITERARIA
}

\author{
EPISTEMIC APPROXIMATION TO LITERARY EDUCATION
}

ENSAYO

Recibido:15-11-13
Wilfredo Illas.*
UC

Aceptado: 06-04-14

\section{RESUMEN}

Comprender la dimensión epistémica que implica la educación literaria representa un verdadero desafío, el cual puede vislumbrarse desde una doble articulación: valorar la proyección educativa del fenómeno literario; $\mathrm{y}$, reconocer la confluencia de lo educativo, lo literario y lo humano en instancias relacionales, dialógicas y vivenciales. El propósito de este ensayo científico consiste en delinear algunos elementos epistémicos de la educación literaria como instancia inaplazable para enriquecer el mundo del alumno/lector desde dimensiones cognitivas, afectivas, espirituales y culturales. Vista así resulta válido pensar una educación literaria recreada en la promoción de la literatura local y regional que vehicule la condición humana en la comprensión de los múltiples sentidos y significados a los que el texto apuesta, suscitando el desarrollo de una actitud favorable hacia los valores identitarios y hacia una lectura más afectiva y significativa que, desde el imaginario literario circundante, sumerja al lector en el periplo literario universal.

Descriptores: educación, literatura y episteme.

\begin{abstract}
Understanding the epistemic dimension literary education implies represents a real challenge which can discern from a double articulation: to value the educational projection of literary phenomena; and, to recognize the confluence from the educational, literary and human aspects in relational, dialectical and experiential moments. The purpose of this essay is to outline some epistemic elements of literary education as the instance to enrich the students/reader's world from different cognitive, affective, spiritual and cultural perspectives. It is valid to think a literary education recreated in the promotion of the local and regional literature that moves the human condition in the comprehension of multiple senses and meanings, causing the development of a positive attitude to the values and to develop a more significant and effective reading skill that, from the imaginary surrounding literary, submerges the reader in the universal literary long journey.
\end{abstract}

Keywords: Education, literature, episteme

\footnotetext{
* Profesor de Literatura UPEL-IPB, Magíster en Literatura Venezolana U.C, Doctor en Educación U.C, Especialista en Educación de Adultos UNESR, Postdoctor en Educación U.C, Postdoctor en Ciencias Humanas L.U.Z. Profesor de Teoría y Análisis Literario. FaCE-U.C Correo Electrónico: illasw@hotmail.com
} 


\section{INTRODUCCIÓN}

Podemos entender por educación literaria al conjunto de elementos didácticos y metodológicos alrededor de los cuales se organiza la enseñanza formal de esta área artística. Básicamente la manera cómo se gestionan los procesos educativos en literatura, generan no sólo la posibilidad de leer y comprender los complejos informacionales, temáticos, lingüísticos y literarios que se estructuran alrededor de un texto; sino que suscitan la integración y la inter y transdisciplinariedad del conocimiento que se pone de manifiesto en todo discurso literario.

La educación literaria no sólo relaciona a un mismo tiempo, la concepción del hombre, de la educación y de lo literario, sino, que puede también, involucrar a varias disciplinas en el análisis del binomio educación-literatura tales como la filosofía, la psicología, la sociología, estética, axiología, entre otros. Si bien lo literario es en su seno interdisciplinario, la educación literaria no escapa a esta dimensión y se articula con múltiples aristas que conforman el sistema de relaciones humanas, el conocimiento multidisciplinar y la interacción con el entramado sociocultural. Todo ello supone la comunión de actitud, tanto del maestro como del estudiante, frente al fenómeno literario, cuya actitud motivada por lo cautivador y vivencial, permitirá la inserción estelar de la literatura y de su significado en la praxis pedagógica.

En relación a lo antes expuesto tenemos que lo literario estaría representado, obviamente, por el texto literario el cual se dirige a un lector implícito y plantea ciertas estructuras discusivas y semánticas tales como: lenguaje, tradición, cultura, temas y motivos, normas y convencionalismos, aportes estéticos, sistemas axiológicos, complejos ficcionales y múltiples dimensiones de lectura, que permiten asignarle un valor interior no sólo desde la necesidad expresiva de quien escribe, sino desde la configuración psicológica, social, cultural, sentimental y vivencial de quien lee. De allí que en el ámbito literario se hable de una lectura interna que permite leer espiritual y emocionalmente no a un escritor, sino a nosotros mismos. Al respecto, afirma Casare - citado por Navas (1988), lo siguiente:

Si el lector es contemporáneo del escritor, su interpretación pone en evidencia en el texto los signos más sobresalientes de su pertenencia a un época (y a un lugar), en ausencia de la cual carecería de sentido. Si el lector pertenece a otra época, se da pronto cuenta de que posee una "competencia” diferente a la del 
escritor; deberá ejecutar como el crítico, y si hace falta ayudado por el crítico, una seria de maniobras de sintonización y de control (...) (p.54)

En este sentido, el marco epistemológico de la educación literaria, estaría organizado en tres fuentes, a saber: las textuales (representadas por la estructura textual y las estéticas de recepción y análisis de texto), las contextuales (representadas por el conjunto de referencias al autor o al lector en sus dimensiones psicológicas, filosóficas, sociales, históricas y culturales) y las inter y transtextuales-disciplinares (relación del texto literario con otros lenguajes del arte, con otras disciplinas, discursos y retóricas). Estas fuentes epistemológicas proporcionan, además, niveles de apertura para lo que sería el análisis semiótico y pragmático del texto literario. Ello implica el reconocimiento de éste como un objeto de arte en el que se transforman, dialogan y complementan otros textos o discursos artísticos - literarios, los cuales no sólo reflejan el inconsciente individual y colectivo, sino que, además, constituyen vehículos para la transformación de ideas y valores que plantean, entre otros beneficios, posibilidades de comunicación

\section{DESARROLLO}

Entendiendo el hecho didáctico como actividad comunicativa relacional al igual que la literatura, se puede dimensionar la educación literaria a partir del enfoque que busca herramientas, instrumentos y métodos a los fines de hacer más accesible, placentera y manejable la enseñanza del acontecimiento literario. En este sentido, es fácil observar cómo confluye, por una parte el constructo teórico que fundamenta lo educativo(psicología del aprendizaje, recursos instruccionales, métodos de intervención didáctica) y por otro, el entramado conceptual que sustenta la aproximación literaria (teorías y críticas literarias); ambos escenarios poseen un componente pedagógico porque se constituyen en puentes y mecanismos relacionantes para que los lectores se aproximen a las obras, las interpreten e interpelen y sean capaces de desplegar el abanico de posibilidades interpretativas que éstas proyectan. Ello convoca las múltiples discursividades que cohesionan el hecho didáctico con el literario y que implican la necesidad de reflexionar en torno a la proximidad de la escuela, la vida y la literatura. 
Cada creación literaria, a través de las distintas categorías expresivas, devela o proyecta un evento social, el cual expresa valores, preceptos y visiones que del universo posee una cultura. En ese sentido, cada texto sugiere multiplicidad de lecturas, en un proceso signado por el contacto personal e íntimo entre el lector y el texto, sin intermediarios. De allí que la literatura debe cautivar, por lo que las destrezas de análisis vienen a ser sólo herramientas que favorecen la comprensión. En esta suerte, el entendimiento vendrá de la mano del placer y encantamiento por la lectura. Visto así, el interés radica en formar un buen lector y no un crítico literario. El educando aceptará a la literatura sólo si le encuentra un sentido y si ésta le proporciona algún beneficio para comprender, recrear o enriquecer su vida personal.

Resulta conveniente que el docente enfoque la enseñanza de ésta, resaltando las relaciones del texto, en su dimensión ética y estética con la vida misma. He aquí la posibilidad que generaría, por ejemplo, la literatura local - regional: manejar una enciclopedia cultural y vivencial para la significatividad de la lectura, suscitar un encuentro entre el lector y las venas culturales que caracterizan su entorno; y, despertar una necesidad expresiva y re-creacional que se constituyan en motivación para la producción literaria.

En consecuencia, y a la luz de estas perspectivas, se estará formando un lector constructor de sentidos alrededor de los textos literarios, productor de juicios de valor que estructurará a partir de su enciclopedia cultural, vivencial y social. Todo ello sirve de marco para suscitar el conjunto de operaciones interpretativas que dependen, en suma, de su voluntad lectora.

Obsérvese que este panorama epistémico nos plantea una visión de educación literaria que sirve como pretexto para el vínculo escuela-vida-obra, lo cual se convierte en terreno fértil para la promoción de la literatura local - regional dado que ésta generaría relaciones y experiencias significativas de lectura. En esta suerte de resonancia lectora el texto literario representa un punto de encuentro y confluencia de valores, símbolos, imaginarios, visiones de mundo, enriquecimientos culturales, intercambio social, en fin, en espacio recreador de la condición humana.

Vista así, la lectura tendría un carácter significativo y constructivista expresado desde el enriquecimiento y reconocimiento de la enciclopedia cultural y vivencial. Aunado a ello, permitirá un encuentro favorable entre el lector y su cotidianidad circundante, destacando 
aquí una dimensión axiológica orientada hacia lo identitario. Todo este marco referencial plantea la necesidad expresiva que no sólo conjuga en el acto de la lectura aun otro y a un yo, sino que se constituye en ventana para mirar el mundo interno y externo, reconocerse y valorar la riqueza que se oculta en el diario vivir de nuestros pueblos y comunidades.

\section{Dicotomía epistémica, ¿es posible hablar de educación literaria?}

El desarrollo de toda actividad didáctica en el ámbito literario implica por una parte, un acercamiento afectivo y efectivo entre el lector y el texto; y, por la otra, un conocimiento epistémico del propio objeto; es decir, de la naturaleza de lo literario. Al respecto afirma Álvarez (2004), lo siguiente:

...la enseñanza de la literatura suele omitir con perversa naturalidad la definición de su propio objeto, es decir, de la literatura misma, eludiendo incluso entregarse a una reflexión profunda y sin prejuicios sobre la naturaleza de esta institución... Esta resistencia a reflexionar expresamente sobre la condición del fenómeno literario tiene repercusiones tanto en el proceso de enseñanza como en la conceptualización de la disciplina. (p.13)

Sin embargo, el abuso a las visiones netamente teóricas y a las aproximaciones eminentemente técnicas con el texto literario no son del todo provechosas, por el contrario, ello restaría espontaneidad de los propios gustos, intereses y apreciaciones del lector; además, ocasionaría una especie de distanciamiento entre éste y la propia obra. No obstante, lo más lamentable es que ni forma en los estudiantes una actitud gozosa en la lectura ni les recrea en los escenarios vitales a los que el texto remite. En este aspecto, afirma Rosenblatt (2002):

Demostrar la comprensión de una obra ha consistido sobre todo en parafrasear, definir, aplicar los rótulos (teóricos) adecuados... No tiene nada sorprendente que tan pocos, aun de los graduados universitarios, se hayan formado el hábito de volverse a la literatura por placer... La novela... el poema, han sido convertidos para ellos en algo sobre lo que tiene que saber, algo que hay que resumir, analizar o definir, algo que se tiene que identificar como uno podría identificar... o definir las cualidades de un elemento químico determinado. (pp.83-84)

En este sentido, la naturaleza de lo literario no debe entenderse como la separación entre saber (de) literatura y disfrutar (con) la literatura; es decir, dimensionar el texto como 
objeto de análisis y teorización o como escenario vital donde el lector descubre la condición humana, lejos de esta distinción estéril, el acercamiento literario debe privilegiar la convocatoria a leer, posteriormente, dar cabida a los propios discernimientos del lector en relación a los mundos posibles que el texto remite y los mundos propios de la vida que se han recreado en el discurso; por último, generar espacios de reflexión para determinar y conceptualizar la propia naturaleza literaria a partir de la experiencia con el libro. Rosenblatt (ob.cit) refiere:

...todo el conocimiento que tenga el estudiante sobre la historia de la literatura... será una carga inútil si no se lo ha llevado primordialmente a buscar en la literatura una experiencia personal vital... Lejos de guiar al alumno en esa dirección, mucha de la enseñanza de la literatura tiene el efecto de alejarlo de ella... En muchos casos hay un abismo entre cualquier cosa que el joven pueda sentir realmente acerca del libro y lo que el profesor... piensa que debería advertir... Esto... lleva al alumno a considerar la literatura como algo académico, ajeno a sus propias preocupaciones... (pp.85-87)

Esta perspectiva que “enmascara” de tecnicismos y teorizaciones al verdadero deleite literario pudiera tener dos razones fundamentales: por una parte existen profesores de literatura que, desde su particular visión, consideran que ésta no se enseña, negando así toda vinculación del hecho didáctico con el escenario literario, fundamentándose en que "no se sale de una clase de letras con la capacidad para escribir, ni aún en teoría”(Dubrosvky 1969) -citado por González(2006, p.20). A partir de esta afirmación, la clase de literatura es sólo un escenario para “explicarla/comentarla”, surge aquí el segundo eje crítico, ésta (la clase de literatura) es entendida como un encuentro magistral en el cual el docente "sabelotodo" explica cómo acercarse a la obra, da grandes discursos de épocas y movimientos y proporciona como cierta y universalmente “válida” su propia apreciación del texto, por su parte "los estudiantes se sientan, sin tomar parte, y miran al instructor... reaccionar ante las obras de arte”-Rosenblatt (ob.cit, p.85)

En atención a lo antes expuesto, pensar que la literatura no posee fuertes vínculos con lo didáctico es negar no sólo la naturaleza epistémica y de oficio del profesor de literatura, sino, desconocer el aporte social, psicológico, filosófico e histórico que la literatura ha hecho para el conocimiento humano, sería dejar de reconocer, además, cómo las ciencias humanas han nutrido (y se han nutrido) en la definición y fundamentación del 
propio epísteme literario. Para Rosenblatt (ob.cit) negar la vinculación de la literatura con lo didáctico y lo moral es una “ceguera” ante la naturaleza y el valor de la literatura. Al respecto considera:

...cuando se entiende plenamente la experiencia literaria, resulta evidente que los profesores de literatura han sido bastante miopes. No siempre se han dado cuenta de que, quieran o no, afectan el sentido que el estudiante tiene acerca de la personalidad y de la sociedad humana... (el cual) se presenta en su forma más fácilmente asimilable, en la medida en que emerja de una experiencia íntima y de situaciones humanas específicas con toda la agudeza y la intensidad del arte. (pp.30-31)

Ahora bien, el hecho literario es un evento comunicativo por excelencia, no sólo por el tránsito comunicacional que se da en el proceso de recepción, sino, porque cada obra hace una representación artística del “yo” creador y del “otro” destinatario; es decir, se estrechan en un acto humano escritor y lector, en un diálogo además de lingüísticocomunicativo, vivencial. Es ésta otra razón para considerar válido el término educación literaria, y es que, la riqueza formativa que deriva del enunciado estético verbal, enriquece las dimensiones del lenguaje, las visiones de mundo y las posiciones dialógicas en torno a la condición humana. Para González (ob.cit) toda obra literaria es una representación del otro, el cual asume voz y conciencia en el discurso, esas voces y conciencia hablan de diálogos y son éstos los que proporcionan posibilidades pedagógicas. Al respecto afirma:

...nuestra propuesta parte del principio de que la literatura no se "enseña”, en el sentido clásico de transmitir un discurso ajeno para ser repetido por otro u otros, sino que pueden crearse condiciones para comprenderla y disfrutarla, para generar interacciones dialógicas con ella y, que la didáctica, que surge en el proceso epistemológico de cada arte... puede concebirse como un acontecimiento del diálogo estético y de saberes, que se escenifican en el aula de clases, espacio donde convergen múltiples actores... que están dotados de un lenguaje vivo impregnado de resonancias vocales, y, de las voces de la cultura, que transciende el aula...(p.69)

A partir de estas premisas queda entendido que la clase de literatura (o encuentro de educación literaria) es un espacio para diálogos entre las voces de escritores, obras, alumnos, docentes; así mismo, se convierte en instancia propicia para el intercambio tanto de las voces ideológicas, culturales, axiológicas, éticas, estéticas, políticas, entre otras que integran el discurso del conocimiento humano; como de aquellas que le son propias a 
disciplinas que se nutren y nutren a la vez al fenómeno literario, piénsese en la historia, sociología, psicología; y por supuesto, la “transmisión” de la literatura, lo que sugiere a su vez, el hecho de la poca efectividad que pudiera tener la clase magistral como evento instruccional, en el cual la voz “única” sería la del docente y el conocimiento pasaría por el sesgo subjetivo de su propia percepción. De allí que no se daría una posibilidad certera de diálogo, poco se generarían espacios para el discernimiento y el enriquecimiento del gusto lector, para argumentar posturas y encontrar resonancias de las propias experiencias vitales en el texto. En este sentido, resultan válidas las anotaciones de Colomer (2005) cuando refiere:

"No me gusta un poema hasta que el profesor lo explica”, nos decía un adolescente en una entrevista. Con esta cita no pretendemos defender la clase magistral como sistema didáctico habitual. En realidad ésa es la mejor manera de mantener a las jóvenes mentes en la pasividad más complaciente. Se necesitan dispositivos didácticos que lleven a la relectura, el descubrimiento o la construcción de un sentido que el alumno debe poder explicar hasta un cierto punto y confrontar con el obtenido por los demás (pp.57-58)

Con base en estas premisas, queda claro por una parte que, aunque resulte complejo hablar de educación literaria, dado que aún se está definiendo lo literario y dentro de éste, la posibilidad y vigencia real de si la literatura puede efectivamente enseñarse, es innegable el vínculo histórico que se ha suscitado en el devenir cultural entre la literatura y la educación, lo que permite apostar por el concepto educación literaria como propuesta metodológica para el tratamiento y aprovechamiento de la literatura en la escuela. Pensar el discurso literario a la luz de sus posibilidades didácticas, no es más que reivindicar el poder formativo, que como producto agregado, proporciona la literatura al desarrollo cultural, humano y cognitivo del hombre.

La educación literaria, por otro lado, no debe descansar en el discurso unilateral del docente; lo que implica de manera perentoria el surgimiento de propuestas que le permitan al estudiante, desde la intimidad de sus lecturas, construir significados, llegar a teorizaciones que, surgidas desde su propia búsqueda y análisis, se nutran de la experiencia con la lectura de obras literarias y se maticen en los diálogos y discusiones suscitadas entre todos los actores de la clase. 
Entendida desde esta perspectiva, lo educativo literario se articularía desde la producción de significados tanto de la relación humana que se convoca en la lectura y en la clase, como de los discursos, enunciados, conocimientos, visiones de mundo, posibilidades de lectura y lectores que se balancean en la significación del texto literario. Esta producción de significados es una instancia humana que permite construir sentidos, transformar la realidad, redescubrir la magia de los mundos posibles construidos con la palabra; es decir-según Pavel (1994, p.60)- mundos ficcionales que se recrean en la obra y que constituyen una alternativa posible de nuestro mundo real. Todo ello con el interés de propiciar espacios ricos en posibilidades interpretativas, reconocer en lo literario ámbitos de relación y encuentro con el otro; en fin, comprender que cada producto literario es parte de la experiencia vital que se traduce en diálogo, identificación, construcción de sentidos, confluencia de discursos, convocatoria de contextos y relación de posibilidades interpretativas.

\section{Literatura y escuela: desarrollo de la competencia literaria}

A modo iniciático, es conveniente precisar que, aunque la competencia literaria está constituida por dos subcompetencias (recepción del mensaje literario y producción de textos con intención artística), para este trabajo, se abordará con especial interés el desarrollo de la competencia receptora del discurso literario, entendiendo que ésta constituye el eslabón fundamental para el ulterior desempeño en instancias de creación estética - verbal. Sin menoscabo de la subcompetencia relacionada con la producción, se apuesta por el pleno ejercicio de habilidades comprensivas del texto literario (interpretación, valoración, apreciación, análisis, crítica, reflexión) que redundarán en posibilidades de creación (yo creador, particulares necesidades expresivas, recreación de imaginarios, modelos y proyecciones de visiones de mundo)

La competencia literaria desarrolla habilidades de expresión con la ampliación de recursos estilísticos que el estudiante podrá emplear, opcionalmente, para utilizar la lengua como medio de expresión de vivencias y sentimientos. La competencia literaria forja la manifestación de un conjunto de destrezas lingüísticas plenas, madurando así las bases de una competencia comunicativa. Por lo tanto, un estudiante tendrá sólido desarrollo de la competencia literaria cuando: lea e interprete efectivamente un texto literario, conozca los 
referentes socio-culturales y socio históricos que subyacen tanto en la producción como la recepción del discurso, seleccione con autonomía y criterio textos literarios que se adecuen a su interés, motivación y gusto lector, disfrute con la literatura; e, incorpore la literatura a su vida cotidiana. Para ampliar esta idea, resultan validos los planteamientos de Culler (1978), que al respecto manifiesta:

Como la literatura es un sistema semiótico de segundo orden cuya base es una lengua, el conocimiento de la lengua nos hará avanzar algo en el encuentro con los textos literarios... Quien carezca de ese conocimiento, quien no esté versado en absoluto en literatura ni esté familiarizado con las convenciones por las cuales se lee la ficción se sentirá completamente desconcertado ante un poema. La conversación primordial es lo que podríamos llamar la regla de la permanencia: léase el poema como si expresara una actitud relativa a algún problema referente al hombre y/o a su relación con el universo.(pp.40-41)

De estos aportes se puede inferir que la competencia literaria no sólo estará representada por un conjunto de habilidades que serían adquiridas por el lector luego de su vínculo constante con los productos literarios; sino, además, por los retos que deberá enfrentar en su aventura por (y con) los libros. Es decir, la competencia literaria supondría el siguiente ciclo: el conocimiento de la lengua sumado al encuentro experiencial con la literatura forjarían una convención de pertinencia (comprender el discurso y encontrarle un significado) que unida al hábito de la lectura y al deleite literario, serían las bases para la formación de un lector ideal capaz de participar efectivamente en todas las operaciones interpretativas que el texto le ofrece a los fines de explicar la gama de significados aceptables que puedan tener las obras. Culler (ob.cit) sostiene que:

En ese tipo de interpretación (es), el significado de la palabra es lo que revela al lector, mediante las acrobacias en que le hace participar, en relación con los problemas de su condición, como homo significans, creador y lector de signos. Así pues, la noción de competencia literaria acaba haciendo de base de una interpretación reflexiva... (la cual) es diversa, personal y no sujeta a la legislación normativa de presuntos expertos... (pp.46-47)

Ahora bien, si es cierto que los conocimientos lingüísticos son sólo un aporte para el desarrollo de la competencia literaria, también se requieren de aspectos contextuales o de lo que se denomina enciclopedia cultural y referencia vivencial. Al respecto, el ámbito contextual de la comunicación literaria (lector-obra-autor) permitirá insertar a los 
alumnos/lectores tanto en la tradición cultural a la cual pertenecen como a la tradición histórica/literaria, así mismo les ofrecería insumos para interpretar a los textos como a las múltiples perspectivas de la realidad que subyace a éstos. En torno a la competencia literaria a partir de estas especificaciones, Cassany (1998) refiere lo siguiente:

La formación de lo que podemos llamar competencia literaria, no es una tarea exclusiva del área de lengua y literatura, sino del proceso complejo de formación de la persona. No solamente la escuela y la enseñanza formal, sino también el ambiente familiar y social, van proporcionando al alumno las experiencias diversas que desarrollan progresivamente sus capacidades de recepción y apreciación de los mensajes literarios. Se puede afirmar que se trata de la capacidad general de percepción, comunicación y sensibilidad, que se manifiesta ya desde los primeros años de vida.(p.500)

En este sentido es válido mencionar los alcances que genera el desarrollo de la competencia literaria en los estudiantes. En primer lugar, permite que estos incorporen la literatura a su vida cotidiana, que conozcan los referentes contextuales de la comunicación literaria. En segundo término, a nivel cognitivo, proporciona el dominio de suficientes datos sobre el hecho literario: estilos, técnicas, recursos, obras, épocas y autores. Por último, desarrolla una visión crítica y reflexiva del fenómeno literario. En relación a este planteamiento, Huaman (2004) plantea lo siguiente:

(...) la competencia literaria que hace posible el desarrollo de la capacidad cognoscitiva en el estudiante de una inteligencia emocional esencial para la interacción social y la convivencia cultural. Su aprendizaje permite el desarrollo de una actitud de diálogo o dialógica esencial para la meta de una educación liberadora, la adquisición de habilidades de interlocución que hace posible la concreción de consensos y cooperaciones indispensables para la existencia de una convivencia social, plural y heterogénea, y el conocimiento de marcos discursivos de géneros a partir de los cuales es posible la creación de cualquier nuevo saber.(p.6)

En atención a los planteamientos anteriores y dada la naturaleza de la presente investigación, se apela al sentido crítico-reflexivo del estudiante para la interpretación y análisis de la obra literaria; junto a ello, se apuesta por las infinitas posibilidades que proporciona el diálogo estético para el desarrollo de la competencia literaria. Todo esto, en conjunto, permitirá que el estudiante interprete el hecho literario como un elemento más 
que conforma los signos delineantes de la cotidianidad, la cultura y la existencia humana en toda su dimensión. Para López (1994):

la buena literatura aviva en el hombre el sentido de lo esencial, lo que vertebra la vida humana. De ahí su gran poder formativo. Cada obra literaria valiosa expone en imágenes diversos temas... los somete a las múltiples tensiones de la vida, los clarifica... la buena literatura plasma el juego de la existencia en sus múltiples vertientes.(p.7)

No se trata pues, sólo del desarrollo intelectual de las competencias lingüísticas y comunicativas, se trata de abordar con amplia visión de mundo, las diversas posibilidades interpretativas que el texto proporciona; es decir, jugar con el texto, armar ese rompecabezas textual, llenar los vacios discursivos, re-organizar y re-crear el amplio horizonte proyectado en la obra; en fin, dar significado a esa compleja red de asociaciones y signos que se balancean en ese mundo posible, construido con la riqueza estética verbal; es decir, con el infinito, insondable e impenetrable hechizo de la palabra.

Por consiguiente, la competencia literaria se maduraría progresivamente en tres niveles: la decodificación - interpretación de la obra literaria (visión comunicativa), la aplicación de métodos y contenidos para analizar el texto a la luz de la plurisignificación (visión estética - connotativa); y, la dimensión cultural de la obra (visión axiológica valorativa). Estos niveles cooperan con operaciones de otro alcance como la comprensión, crítica, explicación, reflexión y apreciación del evento artístico literario. Para el primer nivel o nivel primario es necesario el aprendizaje de fundamentos que posibilitarán el ulterior conocimiento. Por su parte, para el segundo y tercer nivel o nivel secundario, es necesaria la experiencia de lectura que permitirá reconocer los rasgos de lo literario y así valorar la obra a partis de efectivos y afectivos procesos de recepción estética. Así que, resulta fundamental que el interés educativo descanse en la lectura y observación del texto literario, logrando como valor agregado la interpretación, comentario y discusión de las visiones de mundo y de los vasos comunicantes que se pueden suscitar entre la vida y la obra. La comprensión e interpretación como vía hermenéutica se postula en tránsito permanente que se desplaza de la experiencia vivencial y cultural hacia la experiencia de lectura y el análisis del mensaje literario. 
La competencia literaria interroga por las necesidades del alumno lector, alimenta el desarrollo de la creatividad e imaginación; y, permite que el texto literario opere como medio constitutivo y formador de una conciencia identitaria a partir de su reconocimiento como parte del patrimonio cultural de los pueblos. En el caso de la literatura local y regional, resultan interesante, a partir de estas consideraciones, dos aspectos: por un lado, la construcción de una conciencia identitaria permite reconocer el poder creador del imaginario individual y colectivo que se balancea en la inmediatez; y por el otro, el encuentro más íntimo con la lectura o con la cercanía contextual del texto, permite penetrar en la magia universal del poder creador del lenguaje o en los complejos temáticos y existenciales que se han deslindado en el devenir histórico del pensamiento literario.

\section{CONCLUSIÓN}

Re-creación, placer, amplia visión de mundo y enriquecimiento cultural parecen ser el resultado de una aproximación educativa en literatura que convoca más que una interacción verbal, un vínculo social de alumnos/lectores, escritores, docentes y la obra misma. Es en este circuito relacional, donde se encuentra el carácter interdisciplinario del binomio educación - literatura. Al respecto, nos dice Calvo (2005):

El estudiante y el maestro, como lectores de ese universo de significación que es el texto literario, se postulan como analistas simbólicos y el espacio académico como ámbito dialógico del encuentro. Los textos literarios son una red de relaciones tanto desde su génesis, proceso de producción; como en el proceso de recepción, en los cuales interactúan los polos de la comunicación: autor y lector... (p.5)

Es evidente el carácter dialógico-relacional de triple articulación en el cual se sustenta la educación literaria: relación texto - lector, relación didáctica alumno(s)-textodocente; y, relación texto-contexto-enciclopedia-vivencia y experiencia de lectura. Este último circuito es transversalizado por el lenguaje en el cual se entrecruzan discursos, producen significados, resemantiza la condición humana, se construye el sujeto, articula la experiencia del hombre, cohesiona y expresa lo social, se materializa el hacer cultural, configura el pensamiento, en fin, se conoce la realidad ficcionalizándola o recreándola.

Se hace evidente el carácter de interacción humana que suscita lo literario y educativo. El lenguaje adquiere una dimensión existencial que posibilita el tránsito de 
saberes, discursos, experiencias, búsquedas y sentidos, constituyéndose en posibilidad de encuentro, realidad y significación. Todos estos escenarios pueden ser aprendidos, disfrutados, conceptualizados y validados tanto desde las perspectivas de recepción que el texto literario despliega como de los eventos didácticos constructivos y transformadores que se puedan generar en el encuentro realidad, vivencia y clase de literatura.

En estos encuentros epistémicos y desde la educación literaria se concibe al estudiante como alumno/lector, sustentándose básicamente en la teoría de la recepción, la cual determina no sólo el carácter cooperativo en la construcción de significados, sino el valor interpretativo y el juicio crítico - reflexivo que asume dicho lector como postura apreciativa del discurso literario. Insistiendo, el texto es un producto inacabado y objeto de significado que requiere de la participación del lector para que este articule saberes, experiencias de lectura y referencias contextuales - vivenciales.

Puntualizando, resulta válido afirmar que la literatura permite enriquecer el mundo espiritual, divertirse y entristecerse, transmitir valores que replantean el sentido de la vida, adquirir conocimientos como productos agregados del discurso literario, producir modelos de comunicación, desarrollar el placer estético y ampliar la visión del mundo.

Los principales problemas de la enseñanza literaria están vinculados a la memorización, repetición sin sentido de información, acumulación de información y al poco ejercicio de actitudes creativas, críticas, analíticas y reflexivas que se constituyen en bastión para el desarrollo de la competencia literaria. A este respecto, nos dice Calvo (ob.cit) que la clase de literatura se ha caracterizado "por una ausencia del estudio profundo de las obras, no se leen los libros se informa sobre ellos, la ausencia del libro trae como consecuencia la ausencia de la teoría y crítica literaria...”(p.2). Al reconocerse ausencia de la crítica literaria, también se reconoce que este aporte no se está integrando satisfactoriamente en la búsqueda de caminos didácticos; es decir, lo literario y lo educativo no se están nutriendo de correspondencias conceptuales y metodológicas que pueden hacer de la praxis educativa en literatura, un encuentro enriquecedor de lo cognitivo, afectivo y espiritual.

Es importante reconocer que, aunque la educación literaria oficial se sustenta en un canon académico que fija las pautas en torno a obras y autores que los alumnos deben conocer existe un conjunto de producciones literarias locales y regionales que nutren el 
conocimiento literario y aproximan al alumno/lector con esos temas y motivos más próximos a su realidad contextual, generando así no sólo una lectura significativa que reivindica el valor de lo identitario; sino la posibilidad de forjar un canon personal o escolar que estaría representado por las obras que se adecuan a las búsquedas, intereses y necesidades particulares de lectura, de allí que los objetivos curriculares deben establecerse como ámbitos referentes que no se reduzcan a retazos o fragmentos de obras, sino que delineen un camino de lectura, que se complemente y reflexione desde el propio contexto sociocultural, para que éste nos lleve a las grandes obras de literatura universal.

En el contexto educativo de la literatura debe destacarse el vínculo de ésta con la vida (obra humana), con la visión de mundo (realidad, tradición, conciencia), con la sensibilidad humana (consuelo, sentimientos), con aquellos problemas filosóficos (vida, muerte, tiempo, conocimiento, angustias existenciales, interrogantes), con el lenguaje (polisemia, expresión, comunicación, recepción) y con otros aspectos que han circundado la preocupación del hombre en todos los tiempos y latitudes. Al respecto, las prácticas didácticas deben privilegiar la relación comunicativa entre los sujetos de acción: lector/lectores, como aquellos que participan en la búsqueda de significados en el texto, el cual se constituye en unidad plurisignificativa y multirelacional; y al autor como constructor de sentidos.

El tratamiento educativo de la lectura se hace transversal no sólo porque se desplaza dialógicamente en el hacer epistémico de las demás disciplinas, sino porque se convierte en punto cardinal y vertebral de todo el objeto educativo; y es que, siendo el lenguaje su materia de creación, la convierte en ámbito indispensable para la adquisición y expresión del conocimiento y para desarrollar procesos cognitivos como asimilar, criticar, reflexionar, crear e imaginar.

Así mismo, el ámbito de la educación literaria es interdisciplinario, dado que para el desarrollo de la competencia literaria, confluyen variadas disciplinas del saber que proporcionan perspectivas más amplias, holísticas e integrales en torno a la experiencia literaria consustanciada con la experiencia vital. Al decir de Colomer (2005) “La literatura se convirtió en un punto de reunión de distintas disciplinas y la idea de su valor como construcción cultural de las personas han sido señalado repetidamente por autores de diversas áreas...”(p.34) 
Entendiendo como fin de la educación literaria el desarrollo de una competencia receptora o productora de mensajes estético verbales, cercana a la significación y sensibilidad ante el hecho literario, se apuesta por una concreción curricular que epistémicamente responda a dos relaciones fundamentales: una de carácter teórico (aprendizaje significativo - constructivo / estética de la recepción) y otro de carácter canónico (canon oficial: literatura universal y nacional fundamental / canon formativo: intereses de lectura y productos de la literatura local - regional). De esta concreción derivaría una relación axiológica con los campos socio - culturales.

Esta precisión del currículo se sustenta en tres pilares: las aspiraciones de la materia (enriquecimiento espiritual y cultural, ampliar la visión de mundo), las orientaciones metodológicas (enseñanza, aprendizaje significativo y constructivista, estrategias) y la proyección pragmática (comunicación, apreciación y valoración literaria). La inserción de la literatura local - regional no sólo responde a estos tres circuitos, sino que exige revisión, selección y adaptación de estas obras a los contenidos planteados y con ello una reformulación y replanteamiento de aquellas aspiraciones retratadas en el diseño o propuesta curricular lo cual proporciona como valor agregado la reivindicación de la investigación, el reconocimiento de lo autóctono como fuente de sabiduría y el desarrollo de una actitud identitaria.

Resulta válido aclarar que las transiciones y adaptaciones de lo local - regional en el currículo, no debe efectuarse a la luz de corrientes, escuelas y movimientos literarios, esto además de temerario y arriesgado pudiera ser fuente de confusiones e inconcreciones innecesarias. La adaptación debe dimensionarse desde los núcleos temáticos (amor, vida, tiempo, aventura, naturaleza) y observar en ellos el devenir de la condición humana, la tradición, recurrencia y el campo axiológico, social y cultural que deriva de los contextos témporo - espaciales tanto universales como locales en que se suscita cada producto literario como recreación de la sensibilidad y visión de mundo.

\section{REFERENCIAS}

Álvarez, J. (2004). Teoría literaria y enseñanza de la literatura. España: Ariel Editores. 


\section{Aproximación epistémica a la educación literaria}

Calvo, M. (2005). Didáctica de la literatura como proceso de significación y desarrollo de la competencia discursiva. Disponible :http://poligramas.univalle.edu.co/24b/didactica.pdf. [Consulta: 2010, Enero 19]

Cassany, D. (1998). Enseñar Lengua.España: Ediciones GRAO.

Colomer, T (2005). Andar entre libros. Lectura literaria en la escuela. México: Fondo de cultura económica.

Culler, J. (1978). La poética estructuralista. Barcelona - España: Editorial Araguana.

Gonzáles, H. (2006). La didáctica del minicuento. Colombia: Ed. Colciencias.

Huamán, M. (2004). Educación y Literatura en el Perú. Lima: Ediciones Mantaro.

López, A. (1994). El análisis literario y su poder formativo. Madrid: Ediciones Rialp

Navas, G. (1988). Niños, Lectura y Literatura. Caracas: Ediciones Gratz.

Pavel, T. (1994). Mundos de ficción. Caracas: Monte Ávila Editores.

Rosenblatt, L. (2002). La literatura como exploración.México: Fondo de Cultura Económica. 